\title{
Komposisi Kimia Batu Kapur Alam dari Indutri Kapur Kabupaten Kolaka Sulawesi Tenggara
}

\author{
Megawati $^{* 1}$, Alimuddin ${ }^{2}$, Laode Abdul Kadir ${ }^{3}$ \\ ${ }^{1,3}$ Universitas Sembilan belas November Kolaka \\ ${ }^{2}$ Universitas Halu Oleo

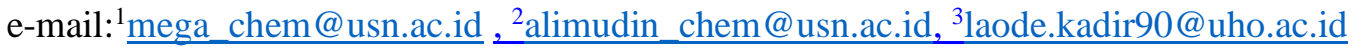

\begin{abstract}
Abstrak
Potensi sumber daya mineral kabupaten Kolaka hampir tersebar diseluruh kecamatan. Ini dibuktikan dengan adanya beberapa perusahaan tambang yang beroperasi di kabupaten Kolaka. Salah satu mineral yang ada di kabupaten Kolaka adalah batu kapur atau yang biasa dikenal dengan istilah batu gamping. Batu kapur ialah jenis batuan sedimen yang umumnya mengandung senyawa karbonat terutama Kalsium Karbonat $\left(\mathrm{CaCO}_{3}\right)$. Pada umumnya batu kapur diolah untuk bahan campuran bangunan, industri, serta bahan kimia bagian sektor katalis. Analisis komposisi batu kapur dari kabupaten Kolaka telah dilakukan dalam penelitian ini. Hal ini dilakukan untuk mengetahui kualitas batu kapur alam Kolaka agar kedepannya bisa menjadi bahan pertimbangan untuk dimanfaatkan lebih lanjut. Hasil analisis menggunakan X-Ray Fluorescence (XRF) menunjukkan komposisi mineral yaitu $\mathrm{CaO}, \mathrm{CaCO}_{3}, \mathrm{Al}_{2} \mathrm{O}_{3}, \mathrm{SiO}_{2}, \mathrm{CaO}, \mathrm{Fe}_{2} \mathrm{O}_{3}, \mathrm{MgO}, \mathrm{Cr}_{2} \mathrm{O}_{3}, \mathrm{Fe}_{2} \mathrm{O}_{3}$, $\mathrm{K}_{2} \mathrm{O}, \mathrm{MnO}, \mathrm{Na}_{2} \mathrm{O}, \mathrm{P}_{2} \mathrm{O}_{5}, \mathrm{ZnO}, \mathrm{SO}_{3}$ dan $\mathrm{TiO}_{2}$.
\end{abstract}

Kata Kunci: Batu kapur, $\mathrm{CaCO}_{3}$, Kolaka, Kalsium Karbonat

\section{PENDAHULUAN}

Kabupaten Kolaka adalah salah satu kabupaten di Sulawesi Tenggara dengan ibu kotanya adalah Kolaka. Kabupaten Kolaka terletak di bagian barat Provinsi Sulawesi Tenggara dengan posisi memanjang dari Utara ke Selatan, tepatnya berada pada $3^{\circ} 37^{\prime}-4^{\circ} 38^{\prime}$ Lintang Selatan dan $121^{\circ} 05^{\prime}-121^{\circ} 46^{\prime}$ Bujur Timur. Kabupaten Kolaka secara geografis berbatasan di sebelah Utara dengan Kabupaten Kolaka Utara, sebelah Selatan berbatasan dengan Kabupaten Bombana, sebelah Timur berbatasan Kabupaten Konawe dan Kolaka Timur, sementara sebelah Barat berbatasan dengan Teluk Bone. Secara administrasi Kabupaten Kolaka pada tahun 2013 terdiri atas dua belas wilayah kecamatan, yaitu Watu bangga, Tanggetada, Pomalaa, Wundulako, Baula, Kolaka, Latambaga, Wolo, Samaturu, Toari, Polinggona, dan Iwoimendaa. Kecamatan Samaturu adalah kecamatan dengan wilayah terluas yaitu $543,90 \mathrm{~km}^{2}$ atau $16,75 \%$ dari total luas Kabupaten Kolaka sedangkan Kecamatan Polinggona merupakan kecamatan dengan wilayah terkecil yaitu 46,65 km²atau 1,44\% dari total luas Kabupaten Kolaka.

Potensi sumber daya di kabupaten Kolaka sangat besar terutama di bidang perkebunan, pertanian, pariwisata dan pertambangan. Hal ini didukung oleh keadaan permukaan wilayah kabupaten Kolaka yang umumnya terdiri dari gunung dan bukit yang memanjang dari utara ke selatan, dan memiliki beberapa sungai yang dijadikan sebagai sumber tenaga, kebutuhan industri, kebutuhan rumah tangga dan kebutuhan irigasi serta pariwisata. Dari sektor pertambangan, kabupaten kolaka cukup melimpah. Hal ini dibuktikan dengan adanya beberapa perusahaan tambang yang beroperasi untuk mengolah sumber daya mineral. Contohnya perusahaan tambang nikel PT. Aneka Tambang tbk yang beroperasi di kecamatan Pomala. Potensi sumber daya mineral Kabupaten Kolaka tersebar hampir di seluruh kecamatannya yaitu nikel, magnesit, pasir kwarsa, batu kapur (gamping), bijih nikel, emas, batu bara, batu sabak, marmer.

Salah satu mineral yang diolah adalah batu kapur (batu gamping) dengan potensi 4,33 Milyar meter kubik. Batu kapur yang diolah di kabupaten Kolaka hanya sebatas industri rumah tangga. Batu kapur alam

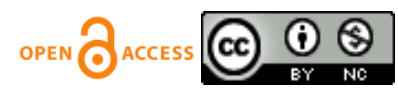


yang diperoleh diolah dengan cara dibakar untuk menghasilkan kapur tohor, atau dikenal dengan istilah kimianya kalsium oksida $(\mathrm{CaO})$. Hasil pembakaran inilah yang dijual untuk kebutuhan bahan bangunan rumah, pabrik tambang, perikanan dan lain sebagainya.

Batu kapur ialah jenis batuan sedimen yang mengandung senyawa karbonat. Pada umumnya batu kapur yang banyak terdapat di alam adalah batu kapur yang mengandung kristal kalsit. Batu kapur memiliki warna putih, putih kekuningan, abu-abu hingga hitam. Pembentukan warna ini tergantung dari campuran yang ada dalam batu kapur tersebut, misalnya : lempung, kwarts, oksida besi, mangan dan unsur organik. Batu kapur terbentuk dari sisa-sisa kerang di laut maupun dari proses presipitasi kimia. Berat jenis batu kapur berkisar 2,6 $-2,8 \mathrm{gr} / \mathrm{cm}^{3}$, dalam keadaan murni dengan bentuk kristal kalsit $\left(\mathrm{CaCO}_{3}\right)$, sedangkan berat volumenya berkisar $1,7-2,6 \mathrm{gr} / \mathrm{cm}^{3}$. (Lukman dkk., 2012). Mineral karbonat yang umum ditemukan berasosiasi dengan batu kapur adalah aragonite (salah satu bentuk kristal $\mathrm{CaCO}_{3}$ ), yang merupakan mineral metastable karena pada kurun waktu tertentu dapat berubah menjadi kalsit (kristal $\mathrm{CaCO}_{3}$ yang paling stabil) (Sucipto dkk., 2007). Seperti yang diketahui bahwa batu kapur mengandung sebagian besar mineral kalsium karbonat yaitu sekitar 95\%. Kandungan kalsium karbonat ini dapat diubah menjadi kalsium oksida $(\mathrm{CaO})$ dengan kalsinasi sehingga lebih mudah dimurnikan untuk mendapatkan kalsiumnya. Dengan cara ini, batu kapur dapat dimanfaatkan dalam sektor katalisis.

Komposisi Kimia batukapur yang pernah dilakukan sebelumnya yaitu dari Kecamatan Banawa, Donggala , Sulawesi Tengah. Dari hasil analisis XRF, batu kapur Banawa termasuk jenis kalsium dengankemurnian tinggi yang tersusun atas unsur $\mathrm{Ca}(96,38 \%), \mathrm{Si}(1,47 \%), \mathrm{Sr}(1,44 \%), \mathrm{Fe}(0,595 \%)$, $\mathrm{Ti}(0,060 \%), \mathrm{Nb}(0,0222 \%), \mathrm{Sn}(0,0123 \%), \mathrm{Sb}(0,0123 \%)$, dan In $(0,0120 \%)$, sementara untuk $\mathrm{CaO}$ hasil kalsinasi pada suhu $950^{\circ} \mathrm{C}$ sebanyak 96,59\% (Suhardin dkk, 2018).Selain itu, Batu kapur di kecamatan Suppa, kabupaten Pinrang, Sulawesi Selatan dianalisis dengan mengkarakterisasi kandungan $\mathrm{CaCO}_{3}$ melalui proses kalsinasi pada suhu 550,650 dan $750^{\circ} \mathrm{C}$ dan diperoleh persentasi kandungan berturut turut $98,8 \%, 92,2 \%$ dan 84,0\%. Komposisi unsur dans senyawa lainnya dapat dilihat pada tabel 1 (Novianti dkk, 2015). Komposisi kimia batu kapur yang pernah dianalisis diperlihatkan pada tabel 2.

Tabel 1 Komposisi unsur dan senyawa oksida hasil analisis EDS sampel $\mathrm{CaCO}_{3}$ pada suhu $750^{\circ} \mathrm{C}$

\begin{tabular}{|c|c|c|c|c|c|}
\hline Element & Unn.C(wt.\%) & Unn.C(wt.\%) & $\begin{array}{c}\text { Unn.C( } \\
\text { wt.\%) }\end{array}$ & Senyawa & Wt (\%) \\
\hline Oksigen (O) & 22,97 & 30,26 & 51,43 & & 0,00 \\
\hline Silikon (Si) & 1,92 & 2,53 & 2,45 & $\mathrm{SiO} 2$ & 5,40 \\
\hline Aluminium (Al) & 1,11 & 1,46 & 1,47 & $\mathrm{Al} 2 \mathrm{O} 3$ & 2,76 \\
\hline Sodium (Na) & 0,12 & 0,16 & 0,19 & $\mathrm{Na} 2 \mathrm{O}$ & 0,21 \\
\hline Potasium (K) & 0,49 & 0,64 & 0,45 & $\mathrm{~K} 2 \mathrm{O}$ & 0,77 \\
\hline Calsium $(\mathrm{Ca})$ & 48,66 & 64,11 & 43,50 & $\mathrm{CaO}$ & 89,70 \\
\hline Total & 75,91 & 100,00 & 100,00 & & \\
\hline
\end{tabular}

Tabel 2 Komposisi Kimia Batu Kapur Hasil Pengujian dengan XRF (Lukmandkk., 2012)

\begin{tabular}{|c|c|c|}
\hline No & $\begin{array}{c}\text { Komposisi } \\
\text { Kimia }\end{array}$ & $\% \mathrm{Wt}$ \\
\hline 1 & $\mathrm{Ca}$ & 92,1 \\
2 & $\mathrm{Fe}$ & 2,38 \\
3 & $\mathrm{Mg}$ & 0,9 \\
4 & $\mathrm{Si}$ & 3,0 \\
5 & $\mathrm{In}$ & 1,4 \\
6 & $\mathrm{Ti}$ & 0,14 \\
7 & $\mathrm{Mn}$ & 0,03 \\
8 & $\mathrm{Lu}$ & 0,14 \\
\hline
\end{tabular}

Kalsiumkarbonat $\left(\mathrm{CaCO}_{3}\right)$ adalah senyawa yang dominan yang terkandung dalam batu kapur. Kalsit $\left(\mathrm{CaCO}_{3}\right)$ merupakan fasekristal yang paling stabil dan banyak digunakan dalam industri cat, kertas, magnetic 
recording, industritekstil, detergen, plastik, dankosmetik (Lailiyah dkk., 2012). Seperti yang diketahui bahwa batu kapur mengandung sebagian besar mineral kalsium karbonat yaitu sekitar 95\%. Kandungan kalsium karbonat ini dapat diubah menjadi kalsium oksida dengan kalsinasi sehingga lebih mudah dimurnikan untuk mendapatkan kalsiumnya. Dengan cara ini, batu kapur dapat dimanfaatkan dalam sektor katalisis.

Dalam tulisan ini peneliti akan menganalisis kandungan/komposisi kimia yang terkandung dalam batu kapur yang digunakan dalam indutri rumah tangga di kabupaten Kolaka. Hasil penelitian ini diharapkan dapat digunakan sebagai acuan untuk pengembangan penelitian kimia mengenai batu kapur khususnya di kabupaten Kolaka dan sebagai sumber informasi komposisi kimia batu kapur.

\section{METODE PENELITIAN}

Bahan yang digunakan dalam peneltian ini adalah batu kapur yang diperoleh dari industrirumahtangga(industri batu kapur rumahan) dari desa Tambea, Kecamatan Pomala, Kabupaten Kolaka. Metode penelitian diawali dengan tinjauan lokasi industri kapur, diskusi terkait dengan industri kapur yang dilakukan sekaligus pengambilan sampel batu kapur dan tahap terakhir adalah tahap pengukuran untuk mengetahui komposisi senyawa dalam laboratorium. Analisis komponen mineral dilakukan di laboratorium Kimia Fakultas Matematika dan Ilmu Pengetahuan Alam Universitas Halu Oleo di Kendari.

Tahap analisis dimulai dari batu kapur dibersihkan menggunakan aquades lalu dikeringkan dalam oven selama 1 jam pada suhu $100^{\circ} \mathrm{C}$. Setelah kering, batu kapur digerus menggunakan mortar dan pastel hingga diperoleh serbuk kapur dan disaring menggunakan ayakan 200mesh. Serbuk kapur yang telah lolos ayakan ditimbang sebanyak 30 gram untukanalisis komposisi mineral. Sampel dibagi menjadi 2 bagian, sampel batu kapur yang tidak terkalsinasi dan sampel batu kapur yang telah dikalsinasi pada suhu $750^{\circ} \mathrm{C}$ dalam tanur selama 3 jam. Karakterisasi dilakukan dengan menggunakan X-Ray Flourescence (XRF).

\section{HASIL DAN PEMBAHASAN}

Penelitian ini diawali dengan pengambilan sampel batu kapur di desa Tambea Kecamatan Pomala Kabupaten Kolaka. Batu kapur yang diperoleh berwarna putih keabu abuan (Gambar1). Batu kapur yang diolah di industri rumahan ini diperoleh dari kecamatan Wolo Kabupaten Kolaka dan Kabupaten Bombana. Hal ini karena tingginya konsumsi batu kapur di wilayah Kolaka dan kecamatan Pomala untuk keperluan industri tambang, perikanan dan lain sebagainya

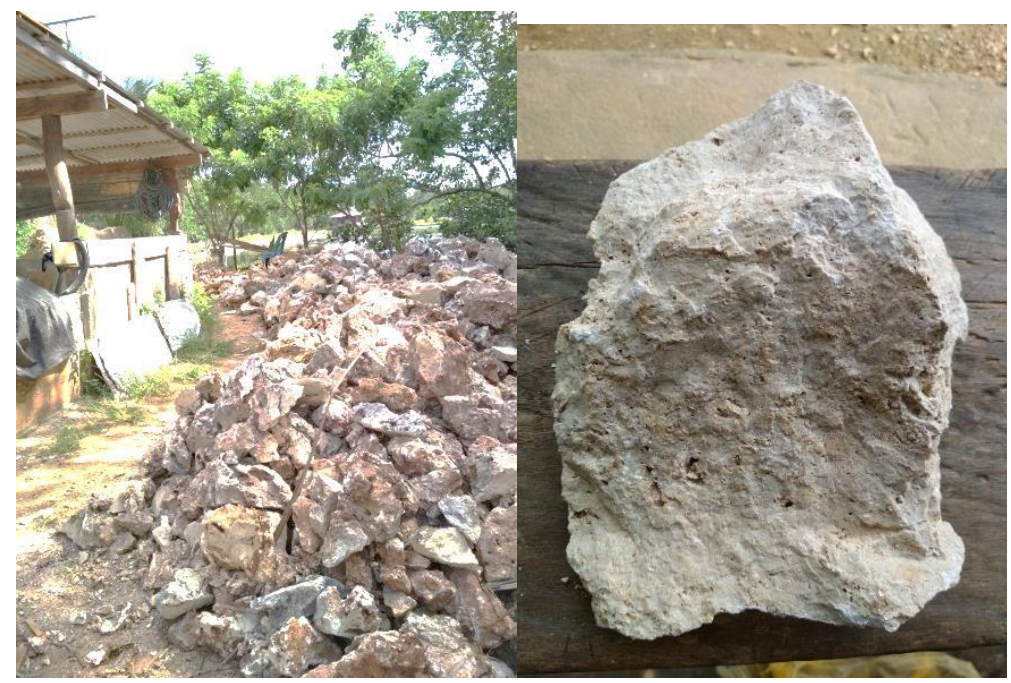

(a)

(b) 


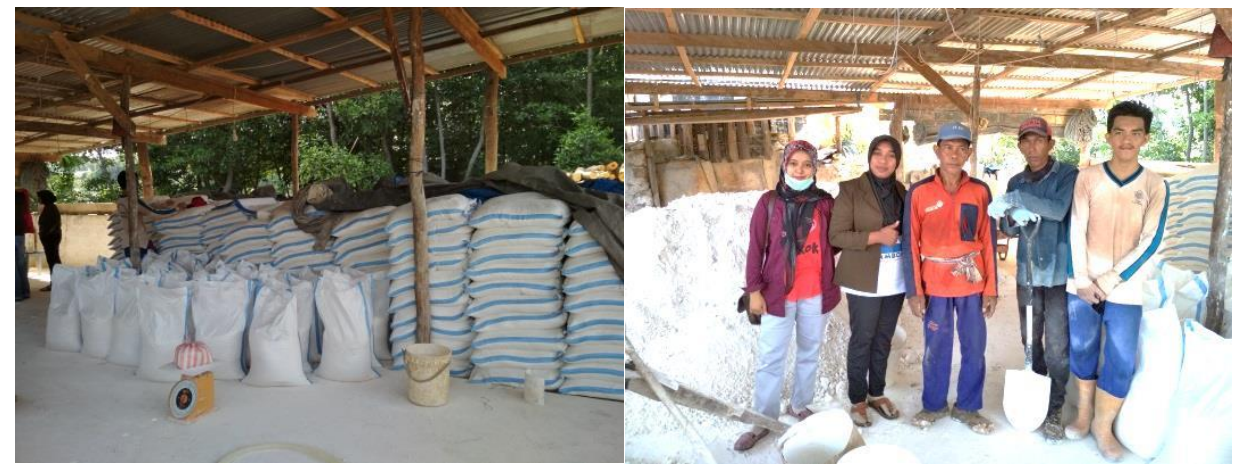

(c)

(d)

Gambar 1 Kondisi industri batu kapur rumahan di desa Tambea, (a) tumpukan batu kapur, (b) bongkahansampel batu kapur, (c) kapur hasil olahan siap dipasarkan, (d)tim peneliti dan pemilik industri batu kapur (tengah berbaju merah) bapak Marsuki

Tahapan selanjutnya adalah preparasi batukapuralam sebelum di analisis lebih lanjut. Tahap preparasi dimulai dari batu kapur dibersihkan menggunakan aquades lalu dikeringkan dalam oven selama 1 jam pada suhu $100^{\circ} \mathrm{C}$ untuk menghilangkan kadar air yang terkandung dalam batuan. Setelah kering, batu kapur dihaluskan dan disaring. sampel yang telah dihaluskan dikalsinasi dengan tujuan untuk menghilangkan senyawa-senyawa organik yang bersenyawa dalam batu kapur alam. Kalsinasi pada suhu $750{ }^{\circ} \mathrm{C}$ selama 3 jam. Kalsinasi dilakukan dengan tujuan untuk menghilangkan senyawa-senyawa organik yang bersenyawa dengan batu kapur alam. Selain itu dengan proses kalsinasi pada temperatur tinggi dapat mengubah hidroksida kedalam bentuk oksida. Komposisi dari batu kapur yang dianalisa dengan pengujian XRF (X Ray Flourescence) dapat ditunjukan pada tabel3. Komposisi batu kapur yang dianalisis terbagi dua yaitu batu kapur yang terkalsinasi dan batu kapur yang tidak terkalsinasi, hal ini dilakukan untuk melihat tingkat perbedaaan kandungan mineralnya.

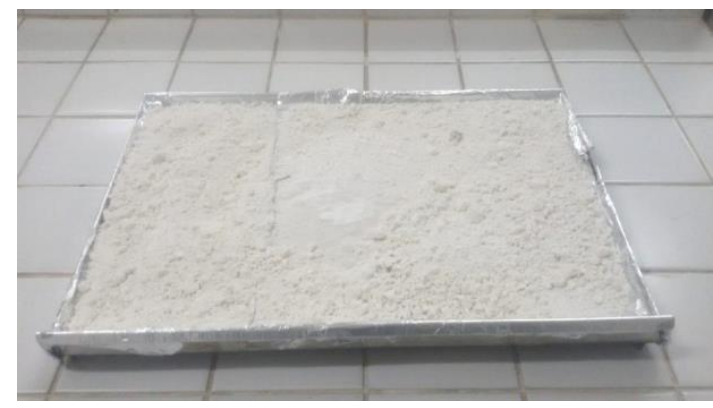

Gambar 2 Batu Kapur hasil kalsinasi pada suhu $750^{\circ} \mathrm{C}$ selama 3 Jam

. Tabel 3 Komposisi batu kapur alam hasil analisis dengan XRF (X-Ray Flourescence)

\begin{tabular}{|c|c|c|c|c|c|c|c|c|c|c|c|c|c|c|c|c|}
\hline \multirow[t]{2}{*}{$\begin{array}{l}\mathrm{N} \\
\mathrm{o} .\end{array}$} & \multirow[t]{2}{*}{ Sampel } & \multirow[t]{2}{*}{$\begin{array}{l}\text { Bera } \\
\text { t (gr) }\end{array}$} & $\begin{array}{c}\mathrm{Ca} \\
\mathrm{O}\end{array}$ & $\begin{array}{c}\mathrm{CaC} \\
\mathrm{O}_{3}\end{array}$ & $\mathrm{Al}_{2} \mathrm{O}_{3}$ & $\begin{array}{l}\mathrm{Cr}_{2} \\
\mathrm{O}_{3}\end{array}$ & $\begin{array}{c}\mathrm{Fe}_{2} \\
\mathrm{O}_{3}\end{array}$ & $\begin{array}{c}\mathrm{K}_{2} \\
\mathrm{O}\end{array}$ & $\begin{array}{c}\mathrm{Mg} \\
\mathrm{O}\end{array}$ & $\begin{array}{c}\mathrm{Mn} \\
\mathrm{O}\end{array}$ & $\begin{array}{c}\mathrm{Na}_{2} \\
\mathrm{O}\end{array}$ & $\begin{array}{l}\mathrm{P}_{2} \\
\mathrm{O}_{5}\end{array}$ & $\begin{array}{c}\mathrm{Si} \\
\mathrm{O}_{2}\end{array}$ & $\begin{array}{c}\mathrm{SO} \\
3\end{array}$ & $\begin{array}{l}\mathrm{Ti} \\
\mathrm{O}_{2}\end{array}$ & $\begin{array}{c}\mathrm{Zn} \\
\mathrm{O}\end{array}$ \\
\hline & & & $\%$ & $\%$ & $\%$ & $\%$ & $\%$ & $\%$ & $\%$ & $\%$ & $\%$ & $\%$ & $\%$ & $\%$ & $\%$ & $\%$ \\
\hline 1. & $\begin{array}{c}\text { Batu } \\
\text { Kapur } \\
\text { terkalsi } \\
\text { nasi } \\
(750 \\
\left.{ }^{\circ} \mathrm{C}\right)\end{array}$ & $\begin{array}{c}10,0 \\
0\end{array}$ & $\begin{array}{l}52, \\
22\end{array}$ & $\begin{array}{c}28,1 \\
6\end{array}$ & 7,85 & $\begin{array}{l}0,0 \\
21\end{array}$ & $\begin{array}{l}<0, \\
01\end{array}$ & $\begin{array}{l}<0, \\
01\end{array}$ & $\begin{array}{l}5,8 \\
22\end{array}$ & 0,1 & $\begin{array}{c}0,6 \\
6\end{array}$ & $\begin{array}{l}<0, \\
01\end{array}$ & $\begin{array}{c}5,3 \\
2\end{array}$ & $\begin{array}{l}<0, \\
01\end{array}$ & $\begin{array}{l}<0, \\
01\end{array}$ & $\begin{array}{l}<0, \\
01\end{array}$ \\
\hline
\end{tabular}


https://jurnal.unsulbar.ac.id/index.php/saintifik

\begin{tabular}{|c|c|c|c|c|c|c|c|c|c|c|c|c|c|c|c|c|}
\hline 2. & Batu & 10,0 & 47, & 32,8 & 8,69 & $<0$, & $<0$, & $<0$, & 7,9 & 0,1 & 0,7 & $<0$, & 3,0 & $<0$, & $<0$, & $<0$, \\
& Kapur & 0 & 53 & & & 01 & 01 & 01 & 45 & & 3 & 01 & 9 & 01 & 01 & 01 \\
\hline
\end{tabular}

Komposis mineral yang terkandung dalam batu kapur hasil analisis tersebut yaitu $\mathrm{CaO}, \mathrm{CaCO} 3, \mathrm{Al}_{2} \mathrm{O}_{3}$, $\mathrm{SiO}_{2}, \mathrm{CaO}, \mathrm{Fe}_{2} \mathrm{O}_{3}, \mathrm{MgO}, \mathrm{Cr}_{2} \mathrm{O}_{3}, \mathrm{Fe}_{2} \mathrm{O}_{3}, \mathrm{~K}_{2} \mathrm{O}, \mathrm{MnO}, \mathrm{Na}_{2} \mathrm{O}, \mathrm{P}_{2} \mathrm{O}_{5}, \mathrm{ZnO}, \quad \mathrm{SO}_{3}$ dan $\mathrm{TiO}_{2}$.Hasil analisisXRFmenunjukanbahwaCaCO3 dan $\mathrm{CaO}$ adalah komponen terbesar dalam batu kapur. Komposisibatukapuralamyang tidak terkalsinasi memilikikandunganCaOdan $\mathrm{CaCO}_{3}$ masing-masingsebesar $47,53 \%$ dan 32,8\%. Sedangkanbatukapuralam yang dikalsinasipadasuhumemilikikandunganCaOdan $\mathrm{CaCO}_{3}$ sebesar 52,22\% dan 28,16\%. Komposisi $\mathrm{CaCO}_{3}$ sebagai komponen utama yang diperoleh cukup jauh dari komposisi $\mathrm{CaCO}_{3}$ pada umumnya yang rata rata diatas $90 \%$. Hal ini kemungkinan disebabkan karena terbentuknya $\mathrm{CaO}$ dari hasil dekomposisi $\mathrm{CaCO}_{3}$ pada suhu tinggi.

Munculnya fase oksida dari kalsium dikarenakan pada suhu $750^{\circ} \mathrm{C} \mathrm{Ca}\left(\mathrm{CO}_{3}\right)$ mengalami dekomposisi akibat energi panas dan membentuk $\mathrm{CaO}$. Berdasarkan referensi dari para peneliti disebutkan bahwa $\mathrm{CaO}$ seringkali dihasilkan melalui kalsinasi $\mathrm{Ca}\left(\mathrm{CO}_{3}\right)$ secara langsung dengan suhu tinggi (Novianti dkk, 2015).

\section{KESIMPULAN}

Komposisi mineral yang terkandung dalam batu kapur dari industri rumahan desa Tambea Kecamatan Pomala Kabupaten Kolaka Sulawesi Tenggara yaitu $\mathrm{CaO}, \mathrm{CaCO}_{3}, \mathrm{Al}_{2} \mathrm{O}_{3}, \mathrm{SiO}_{2}, \mathrm{CaO}$, $\mathrm{Fe}_{2} \mathrm{O}_{3}, \mathrm{MgO}, \mathrm{Cr}_{2} \mathrm{O}_{3}, \mathrm{Fe}_{2} \mathrm{O}_{3}, \mathrm{~K}_{2} \mathrm{O}, \mathrm{MnO}, \mathrm{Na}_{2} \mathrm{O}, \mathrm{P}_{2} \mathrm{O}_{5}, \mathrm{ZnO}, \mathrm{SO}_{3}$ dan $\mathrm{TiO}_{2}$. Hasil analisisXRF menunjukan bahwa $\mathrm{CaCO} 3$ dan $\mathrm{CaO}$ adalah komponen terbesar dalam batu kapur. Komposisi batu kapur alam yang tidak terkalsinasi memiliki kandungan $\mathrm{CaO}$ dan $\mathrm{CaCO}_{3}$ masing-masing sebesar 47,53\% dan 32,8\%. Sedangkan batu kapur alam yang dikalsinasi pada suhu memiliki kandungan $\mathrm{CaO}$ dan $\mathrm{CaCO}_{3}$ sebesar 52,22\% dan 28,16\%. Hasil penelitian ini diharapkan dapat dijadikan acuan untuk analisis lebih lanjut terutama di sektor katalis dalam indutri kimia.

\section{DAFTAR PUSTAKA}

Lailiyah, Q., Baqiya, M., Darminto.(2012). PengaruhTemperaturdanLajuAliran Gas CO2 padaSintesisKalsiumKarbonatPresipitatdenganMetode Bubbling.JurnalSainsdanSeniITS, Vol. 1, No. 1 ISSN: 2301-928X. Surabaya: ITS.

Lukman, M., Yudyanto.,Hartatiek. 2012. Sintesis Biomaterial Komposit CaO-SiO2 Berbasis Material Alam (BatuanKapur Dan PasirKuarsa) DenganVariasiSuhuPemanasan Dan PengaruhnyaTerhadapPorositas, Kekerasan Dan Mikrostruktur.Journal Sains Vol. 2 No. 1. Malang: UM.

Novianti, Jasrudin, dan E. H. Sujiono, 2015, Karakterisasi Kalsium Karbonat (Ca(Co3)) Dari Batu Kapur Kelurahan Tellu Limpoe Kecamatan Suppa, JurnalSainsdanPendidikanFisika. Jilid 11, Nomor 2, hal. 169 $-172$

Sucipto,E.2007.Hubungan Pemaparan Pertikel Debu pada Pengolahan Batu Kapur Terhadap Penurunan Kapasitas Fungsi Paru. Semarang: Universitas Diponegoro.

Suhardin, A., M.S. Ulum, dan D. Darwis, 2018, Penentuan Komposisi Serta Suhu Kalsinasi Optimum CaO Dari BatuKapur Kecamatan Banawa, Natural Science: Journal of Science and Technology, Vol 7 (1) : 30 -35 . 